Research Article

\title{
Association between Biofilm Formation and Susceptibility to Antibiotics in Staphylococcus Lentus Isolated from Urinary Catheterized Patients
}

\author{
Ibtisam Habeeb Al-Azawi ${ }^{1}$, Adnan Hamad Al-Hamadani ${ }^{1}$, Shaimaa Obaid Hasson ${ }^{2}$ \\ ${ }^{1}$ Department of Medical Microbiology, College of Medicine, Al-Qadisiyah University, Iraq. \\ ${ }^{2}$ Department of Microbiology, College of Veterinary, Al-Qassim Green University, Iraq. \\ Corresponding author. E-mail: shaimaaobead@gmail.com
}

Received: Mar. 4, 2018; Accepted: Apr. 8, 2018; Published: Apr. 23, 2018.

Citation: Ibtisam Habeeb Al-Azawi, Adnan Hamad Al-Hamadani, and Shaimaa Obaid Hasson, Association between Biofilm Formation and Susceptibility to Antibiotics in Staphylococcus Lentus Isolated from Urinary Catheterized Patients. Nano Biomed. Eng., 2018, I0(2): $97-103$. DOI: $10.5101 /$ nbe.v10i2.p97-103.

\begin{abstract}
Staphylococcus lentus (S. lentus) is a coagulase negative gram positive cocci recognized as opportunistic pathogens and rarely forming biofilm; it has many virulence factors, but recently caused nosocomial and community infections. Biofilm formation of Staphylococcus lentus may be associated with the ability to resist antibiotics which leads to increase in mortality rate due to the difficulty in eradicate infections. To evaluate the biofilm forming capacity of Staphylococcus lentus and its susceptibility to antibiotics, phenotypic and genotypic assays were used. Among 28 biofilm bacteria, Staphylococcus lentus was isolated and identified from urine catheterized patients who were hospitalized in different departments of four Iraqi hospitals (Al-Diwaniyah Teaching, AlHilla Teaching, Al Qassim and Al Hashimiyah Hospitals). Staphylococcus lentus was examined for detection of biofilm formation by detecting icaA gene, the intercellular adhesion gene which expressed adhesion factor to form biofilm in staphylococci by using polymerase chain reaction (PCR) method and tested for antimicrobial susceptibility by disc diffusion method and VITEK2 system according to guidelines of the Clinical \& Laboratory Standards Institute (CLSI). Three isolates of Staphylococcus lentus revealed the ability to form biofilm phenotypically which contained icaA gene with $100 \%$ antibiotics resistance to penicillin, carbenicillin, gentamicin, tobramycin, oxacillin, vancomycin, clindamycin, ciprofloxacin, and $0 \%$ antibiotics resistance to azithromycin. icaA genes are present in Staphylococcus lentus and responsible for biofilm formation which is considered as the indicator; biofilm formation is a strong cause of multidrug resistance in bacteria.
\end{abstract}

Keywords: Biofilm; Staphylococcus lentus; icaA gene; Antibiotics resistance; Urinary catheterized patients

\section{Introduction}

Staphylococcus lentus (S. lentus) is recognized as opportunistic pathogens and rarely causing infections to human [1], but recently caused nosocomial and community infections [2]. S. lentus is a gram positive, coagulase-negative staphylococci (CoNS); it is mostly infectious to animal species and may colonize humans, which has been reported to have been isolated from various human clinical specimens [3]. CoNS are considered to be an uncertain pathogenic in the urinary tract [4]. However, studies suggested that significance 
of some CoNS as uropathogens may have been undervalued [5]. Conversely, S. aureus is a main cause of urinary tract infection (UTI) among Staphylococcus sp. [6].

Other studies detected that coagulase-negative staphylococci was isolated from biofilms on urinary catheter [7]. Biofilm formation of Staphylococcus sp. could simply be defined as the ability of bacterial cells to adhere with each other and to be surrounded by exopolysaccharide matrix, teichoic acid and extracellular DNA which was regulated by ica ADBC gene expression [8]. The significance of biofilm for catheter-associated urinary tract infection (CAUTI) is that a urinary catheter as a foreign body, entering a normally sterile, hydrated body site and connecting it to the external world will inescapably become colonized with microorganisms [9].

Biofilm-forming pathogens respond poorly to antibiotics to develop antibiotic resistance [10]. Antimicrobial resistance (AMR) has resulted from treatment failures to increase morbidity and mortality, in addition to the high cost of health care, leading to serious world problem according to WHO [11]. Especially, the biofilm production of staphylococci and methicillin resistant strains in addition to antibiotic resistance is one of the most challenging task for physicians and microbiologists [12]. Many local studies showed a high percentage of biofilm formation among Staphylococcus sp. especially CoNS with the ability of multidrug resistance (MDR) [13, 14], but there have been no studies about $S$. lentus exclusively.

The aim of the current study was to evaluate the biofilm-forming capacity of $S$. lentus isolated from urinary tract of catheterized patients and its ability of antibiotic resistance in biofilm forming bacteria by using phenotypic and genotypic assays.

\section{Experimental Collection of specimens}

Twenty eight biofilm bacterial isolates were isolated from urine samples collected from catheterized patients from four Iraqi hospitals (Al Diwaniya Educational, Al Hilla Eductitional, Al Qassim and Al Hashimiya Hospitals) during the period from February to April 2017 in sterile tubes of $10 \mathrm{~mL}$ and then transferred to laboratory immediately.

\section{Bacterial isolate}

S. lentus was isolated from urine of hospitalized catheterized patients which were identified by microscopical characteristics, biochemical tests and novobiocin resistance (novobiocin disc at $5 \mu \mathrm{g}$ ) [15], and then was confirmed by the automated system VITEK 2 (bioMerieux, Marcy I'Etoile, France) to achieve final diagnostics and identification of the species level. In addition, non-biofilm CoNS was used as control.

\section{Phenotypic detection of biofilm}

The biofilm formation was detected by using two methods:

Congo red agar method (quality method) according to Freeman et al. [16]. Black crystalline colonies were considered as strong biofilm producers, dark colonies without dry crystalline colonies as moderate biofilm producers and dark pink colonies as non-biofilm producers.

Tissue culture plate method (TCP) (semi quantity method) according to Christensen et al. [17]. The mean of absorbance value from replicate wells was read; the biofilm degree was calculated according to the following equation:

Biofilm degree $=$

Mean $\mathrm{OD}_{630}$ of tested bacteria - Mean $\mathrm{OD}_{630}$ of control.

\section{Genotypic detection of biofilm}

PCR technique was performed for biofilm formation genes (icaA gene) in (Staphylococcus sp.). The PCR primers were designed by using National Center for Biotechnology Information (NCBI) gene sequence data base and primer 3 plus design. This primer was provided by Bioneer, South Korea (Table 1).

Table 1 PCR primers and their sequence

\begin{tabular}{cccc}
\hline Primer & Sequence $(5 \rightarrow 3)$ & Amplicon size \\
\hline \multirow{3}{*}{ icaA gene } & F & 5-TGGATGTTGGTGCCTGAAAC-3 & \\
& R & AGTACTTCATGCCCACCTTGAG & 77 bp \\
\hline
\end{tabular}

Note: Genbank: icaA: DQ836167.1; F: forward; R: reversed.

\section{DNA extraction}

DNA extraction was done according to manufactured instructions of commercial DNA extraction kit (Presto Mini-DNA Bacteria Kit. Geneaid Biotech Ltd. USA). Then, extracted DNA was estimated by nanodrop device at 260/280 nm. 


\section{PCR master mix preparation}

PCR master mix was prepared from AccuPower®PCR-PreMix-Kit master mix reagent according to the company directions (Table 2).

The PCR mixture revealed in the table above was placed in AccuPower PCR-PreMix that contained all PCR components (Taq DNA polymerase, dNTPs, and 10 PCR buffers). Then, all the PCR tubes were transferred into vortex vibration for $3 \mathrm{~min}$ and transferred into thermocycler apparatus (MyGene, Bioneer. Korea).

\section{PCR thermocycler conditions}

Conditions of the PCR thermocycler are listed in Table 3.

Table 2 Company instructions of PCR master mix

\begin{tabular}{cc}
\hline PCR master mix & Volume \\
\hline DNA template & $5 \mu \mathrm{L}$ \\
Forward primer (10 pmol) & $1.5 \mu \mathrm{L}$ \\
Reverse primer (10 pmol) & $1.5 \mu \mathrm{L}$ \\
PCR water & $12 \mu \mathrm{L}$ \\
Total volume & $20 \mu \mathrm{L}$ \\
\hline
\end{tabular}

Table 3 PCR thermocycler conditions

\begin{tabular}{cccc}
\hline PCR step & Temperature & Time & Repeat cycle \\
\hline Initial denaturation & $95^{\circ} \mathrm{C}$ & $5 \mathrm{~min}$ & 1 \\
Denaturation & $95^{\circ} \mathrm{C}$ & $30 \mathrm{sec}$ & 30 \\
Annealing & $58^{\circ} \mathrm{C}$ & $30 \mathrm{sec}$ & 30 \\
Extension & $72{ }^{\circ} \mathrm{C}$ & $1 \mathrm{~min}$ & 30 \\
Final extension & $72{ }^{\circ} \mathrm{C}$ & $5 \mathrm{~min}$. & 1 \\
Hold & $4{ }^{\circ} \mathrm{C}$ & Forever & - \\
\hline
\end{tabular}

\section{PCR product analysis}

The DNA product was examined by electrophoresis apparatus in a $1 \%$ agarose substance by using buffer, then stained with ethidium bromide, and observed under the UV transilluminator.

\section{Antimicrobial susceptibility testing}

The test was carried out by the following two methods.

\section{Disc diffusion method}

According to Baur et al. [18], antibiotics discs containing penicillin $10 \mu \mathrm{g}$, carbenicillin $100 \mu \mathrm{g}$, gentamicin $10 \mu \mathrm{g}$, tobramycin $10 \mu \mathrm{g}$, oxacillin 1 $\mu \mathrm{g}$, vancomycin $10 \mu \mathrm{g}$, azithromycin $15 \mu \mathrm{g}$ and ciprofloxacin $5 \mu \mathrm{g}$ were obtained from Bioanalysis, India.

\section{Minimum inhibitory concentration (MIC)}

The testing was done by VITEK 2 AST system for antibiotics including benzylpenicillin, oxacillin, gentamicin, tobramycin, levofloxacin, moxifloxacin, erythromycin, clindamycin, teicoplanin, vancomycin, tetracycline, nitrofurantoin, rifampicin, and trimethoprim/sulfamethoxazole.

The results in both methods were regarded as sensitive, intermediate or resistant based on the Clinical and Laboratory Science Institute (CLSI) standard guidelines, M100, 2017 (19).

\section{Statistical analysis}

All experiments were carried out in triplicate to validate the reproducibility of the experiments. Statistical analysis was done by using one way ANOVA at p-value 0.05 by SPSS Statistics 24.0 software.

\section{Results and Discussion}

Out of 28 biofilm formation bacteria isolated from urine samples of catheterized hospitalized patients, $3(10.7 \%)$ of $S$. lentus isolates were recovered and the other 25 (89.3\%) were biofilm formation gram negative bacteria. The results were higher than other studies which isolated $S$. lentus from urine of hospitalized patients at $0.9 \%$ [20] and $0.18 \%$ [5].

Because of fewer studies about S. lentus, it was chosen as the model of gram positive bacteria to study their ability to form biofilm at phenotypic and genotypic levels with relation to antibiotic resistance.

Staphylococcus sp. is the main cause of CAUTI [21]. Several investigators have reported the isolation of $S$. lentus from urine [5]. Bose et al. found that coagulase negative Staphylococci was generally the main cause of biofilm forming on indwelling medical devices [22]. This capability is due to that coagulase negative Staphylococci is capable to produce urease which increases the $\mathrm{pH}$ of urine and effects the formation of calcium and magnesium phosphate crystals which predispose to form biofilm [23]. Biofilm is an assemblage of microbial cells attached to a surface and encapsulated in a film or slime layer of extracellular polymers and can be formed by a wide variety of microorganisms such as both gram-positive and negative bacteria [7]. 
Bacterial isolates that produced biofilm on Congo red media (Fig. 1) where the black color indicated the ability of Congo red dye to stain the polysaccharide matrix which was formed during the biofilm forming process [22].

In TCP method, the bacterial isolates were shown as strong, moderate, weak or non-biofilm production (Fig. 2). The Results were interpreted according to Christensen et al. [17], as shown in Table 4.

The TCP results revealed that $S$. lentus isolates had the ability of strong and moderate degree of biofilm formation with a significant differences between each

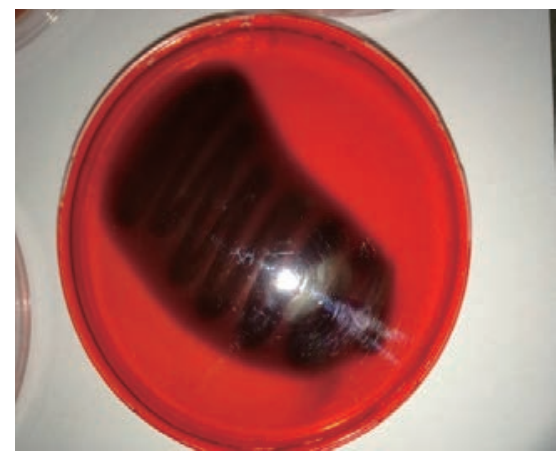

Fig. 1 Congo red agar indicating the biofilm of S. lentus.

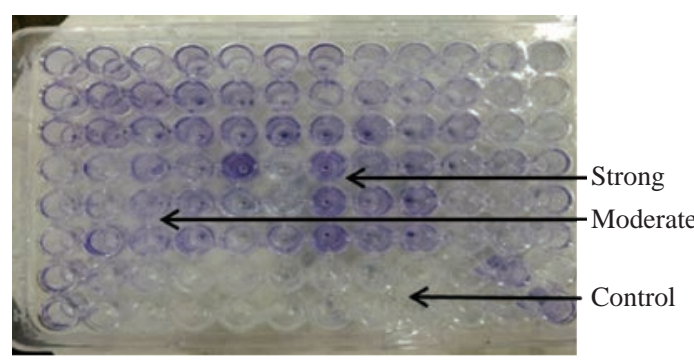

Fig. 2 TCP method indicating the biofilm degree of S. lentus.

Table 4 Classification of biofilm formation according to optical density (OD) values at $630 \mathrm{~nm}$

\begin{tabular}{ccc}
\hline Mean OD value & Adherence & Biofilm formation \\
\hline$<0.120$ & Non & Non/weak \\
$0.120-0.240$ & Moderate & Moderate \\
$>0.240$ & Strong & Strong \\
\hline
\end{tabular}

Table 5 Optical density value of S. lentus biofilm degree according to TCP method

\begin{tabular}{ccc}
\hline Bacteria & Optical density $(630 \mathrm{~nm})$ & Biofilm degree \\
\hline S. lentus 1 & $0.246 \pm 0.00041$ & Strong \\
S. lentus 2 & $0.151 \pm 0.00108$ & Moderate \\
S. lentus 3 & $0.125 \pm 0.00204$ & Moderate \\
\hline
\end{tabular}

Note: Values represent mean \pm S.E. Different capital letters mean significant differences $(\mathrm{p} \leq 0.05)$ between different optical densities other at p-value 0.05 (Table 5).

Staphylococcus sp. mostly can be introduced easily by contaminated medical advices and cause biofilm associated infections via commensal Staphylococcus sp. on skin and mucous surface [12] also S. lentus.

The biofilm formation process was controlled at the genetic level and by environmental signals regulation. The current study focused on the gene listed in Table 1 as the main regulatory gene of bacterial biofilms in the selected strain.

All 3 strains of $S$. lentus were tested for the presence of icaA gene and were found to be positive for it (Fig. 3 ), similar to the findings by Gad et al. that this gene was present in other Staphylococcus sp. (S. aureus, S. epidermidis) [21]. Many researches indicated that ica genes had an important role as the virulence factor of staphylococcal infections associated with urinary catheter [21, 24]. The icaA gene among ica genes has a significant role in biofilm formation in Staphylococcus sp. [25], encoding N-acetylglucosaminyltransferase which is involved in the synthesis of polysaccharide intercellular adhesion (PIA) and $\beta$-1-6-linked poly$\mathrm{N}$-acetylglucosamine polymer (PNAG) that lead to expressing adhesion and capsular polysaccharide phenotypic character [24, 26]. That may explain the ability of Staphylococcus sp. to colonize artificial materials and assist adsorption on biomaterial and solid surface [27]. Other researches showed no biofilm formation by Staphylococcus sp. when negative for icaA gene, which might be due to the lack of the entire ica $A D B C$ operon $[24,28]$. The production of biofilm have several significant advantages, including increased resistance to antibiotics and invading the

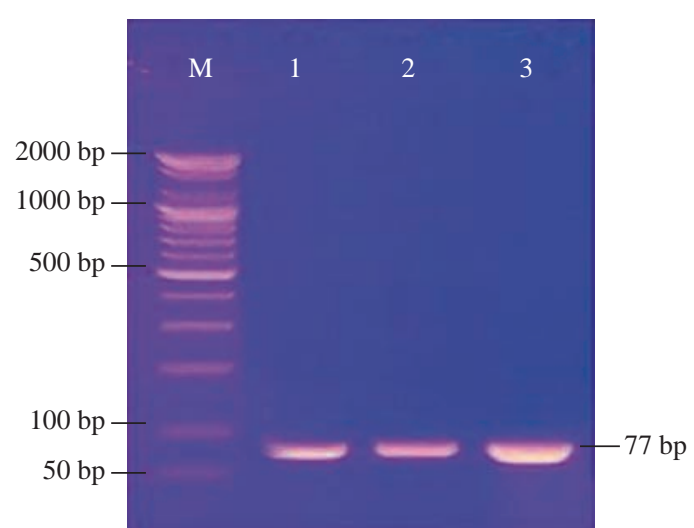

Fig. 3 Agarose gel electrophoresis of PCR assay showed the positive results of biofilm formation of icaA gene in Staphylococcus sp. positive isolates. Lane (M): DNA marker (2000-100 bp); Lanes (1-3): Positive icaA at 77 bp PCR product size. 
immune system which provide a typical environmental for many bacteria [29].

Antibiotic resistance patterns in biofilm forming pathogens were a protective mode to avoid antimicrobial action of traditional antibiotics that aid to persist infection in UTI. The current study focuses on determining and evaluating antibiotic resistance in biofilm forming urobacteria.

S. lentus displayed resistance to multi-antibiotics and was tested in two methods: disc diffusion (Fig. 4 and 5); MIC in VITEK2 AST (Table 7)). In disc diffusion method, the results displayed that 3 isolates of $S$. lentus were resistant to most antibiotics tested in the

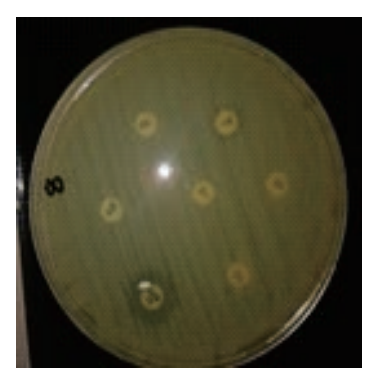

(a)

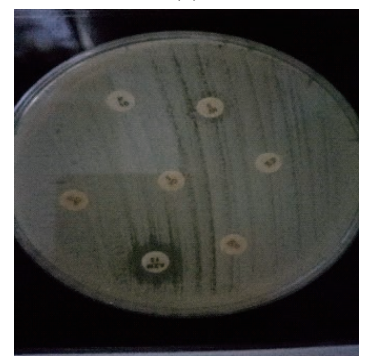

(c)

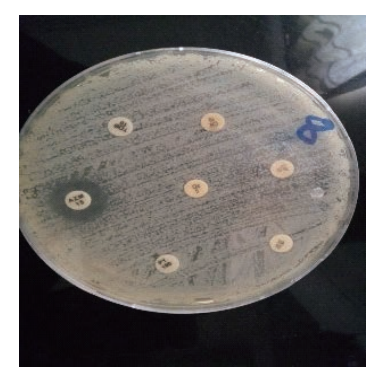

(b)

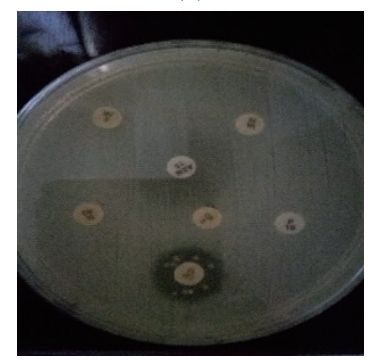

(d)
Fig. 4 Disc diffusion method testing of antibiotic resistance to $S$. lentus isolates (a) S. lentus 1, (b) S. lentus 2 and (c) S. lentus 3; (d) CoNS as control.

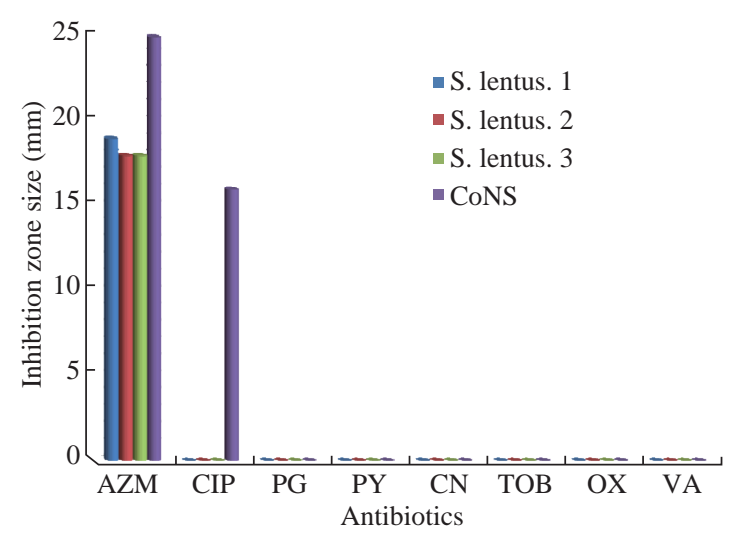

Fig. 5 Zone of inhibition (mm) of different antibiotics in disc diffusion method against $S$. lentus and CoNS as control. (AZM $=$ azithromycin; $\mathrm{CIP}=$ ciprofloxacin; $\mathrm{PG}=$ penicillin $\mathrm{G} ; \mathrm{PY}$ = carbenicillin; $\mathrm{CN}=$ gentamycin; $\mathrm{TOB}=$ tobramycin $; \mathrm{OX}=$ oxacillin; $\mathrm{VA}=$ vancomycin.) experiment. S. lentus isolates revealed a resistance rate of $100 \%$ to each penicillin, ciprofloxacin, carbenicillin, gentamycin and tobramycin, except azithromycin which was effected on $S$. lentus at a resistance rate of $0 \%$ with mean inhibition zone of $18 \mathrm{~mm}$ in contrast to non-biofilm control (CoNS). S. lentus isolates also revealed antibiotic resistance but with high sensitivity to azithromycin at $25 \mathrm{~mm}$ and intermediate to ciprofloxacin at $16 \mathrm{~mm}$ inhibition zone (Fig. 4 and 5) with a significant difference between $S$. lentus isolates and control at p-value 0.05 (Table 6). Many studies have shown that biofilm forming bacteria are more resistant to antibiotics than planktonic bacteria [28, 30, 31]. Azithromycin is a member of the macrolide group, although there are only limited data available about antigram positive biofilm properties of macrolides [32], macrolide antibiotics and especially azithromycin have recently been found to have antibiofilm activity as shown by restrict bacterial quorum sensing, and inhibition of polysaccharide synthesis to prevent biofilm formation and its relation to the ica genes of Staphylococcus sp. [33].

Table 6 Statistical analysis of susceptibility of S. lentus and control to azithromycin according to inhibition zone

\begin{tabular}{cc}
\hline Bacteria & Inhibition zone $(\mathrm{mm})$ \\
\hline S. lentus 1 & $18.00 \pm 0.527$ \\
S. lentus 2 & $\mathrm{~A}$ \\
& $18.00 \pm 0.020$ \\
S. lentus 3 & $\mathrm{~A}$ \\
& $18.00 \pm 0.333$ \\
CoNS & $\mathrm{A}$ \\
& $23.00 \pm 2.888$ \\
\end{tabular}

Note: Values represent mean \pm S.E. Different capital letters mean significant differences $(\mathrm{p} \leq 0.05)$ between different inhibition zones.

In VITEK AST results (Table 7), S. lentus was resistant to all antibiotics. According to CLSI guidelines, the cefoxitin screen which was tested for Staphylococcus isolates predicted results for mecAmediated oxacillin resistance [19]. The mecA gene in Staphylococcus sp. is responsible for antibiotic resistance [34]. VITEK AST revealed that S. lentus was positive for the tested, that is, S. lentus isolates were methicillin-resistant, which was confirmed by oxacillin disc test in disc diffusion test, in addition to its resistance to vancomycin also to be methicillin resistant coagulase negative staphylococci (MRCoNS) and Vancomycin resistant coagulase staphylococci (VRCoNS). Methicillin-resistant staphylococci resisted 
Table 7 VITEK2 antibiotic sensitivity test (AST) system results

\begin{tabular}{|c|c|c|c|c|c|}
\hline Antimicrobial & MIC & Interpretation & Antimicrobial & MIC & Interpretation \\
\hline Beta-lactamase & NEG & - & Erythromycin & $\geq 8$ & $\mathrm{R}$ \\
\hline Cefoxitin screen & POS & + & Clindamycin & $\geq 8$ & $\mathrm{R}$ \\
\hline Benzylpenicillin & $\geq 0.5$ & $\mathrm{R}$ & Teicoplanin & $\geq 32$ & $\mathrm{R}$ \\
\hline Oxacillin & $\geq 4$ & $\mathrm{R}$ & Vancomycin & $\geq 32$ & $\mathrm{R}$ \\
\hline Gentamicin & $\geq 16$ & $\mathrm{R}$ & Tetracycline & $\geq 16$ & $\mathrm{R}$ \\
\hline Tobramycin & $\geq 16$ & $\mathrm{R}$ & Nitrofurantain & 256 & $\mathrm{R}$ \\
\hline Levofloxacin & $\geq 8$ & $\mathrm{R}$ & Rifampicin & $\geq 32$ & $\mathrm{R}$ \\
\hline Moxifloxacin & $\geq 8$ & $\mathrm{R}$ & Trimethoprim/Sulfamethoxazole & $\geq 320$ & $\mathrm{R}$ \\
\hline Inducible clindamycin resistance & NEG & - & - & - & - \\
\hline
\end{tabular}

Note: $\mathrm{R}=$ resistant

all b-lactam antibiotics (cephalosporins, penicillins) and aminoglycosides, which has been considered as multi-drug resistance (MRD) [19, 35].

In addition to the reasons above, many factors lie beneath the ability of bacteria to resist antibiotics, one of which is the biofilm. In this study, the biofilmforming bacteria displayed significantly high antibiotic resistance, which was correspondent to other studies $[30,31]$. In the biofilm state, the antibiotics were more difficult to diffuse into the bacteria, and the compounds of the matrix bound to the antibiotics also increased the difficulty [36]. In addition to their grade of nutrients and oxygen viability, different metabolic states also depend on their depth inside the biofilm layers which affect bacterial susceptibility to antibiotics [30].

\section{Conclusions}

From this study, it was found that the icaA genes present in $S$. lentus were responsible for biofilm formation as the cause genes and could be considered as the indicator of biofilm. The biofilm formation was a strong cause of multi-drug resistance in bacteria.

\section{Conflict of Interests}

The authors declare that no competing interest exists.

\section{References}

[1] S. Stepanovic, P. Ježek, D. Vukovic, et al., Isolation of members of the Staphylococcus sciuri group from urine and their relationship to urinary tract infections. J. Clin. Microbiol, 2003, 41: 5262-5264.
[2] F. Koksal, H. Yasar, and M. Samasti, Antibiotic resistance patterns of coagulase-negative Staphylococcus strains isolated from blood cultures of septicemic patients in Turkey. Microbial. Res, 2009, 164: 404-410.

[3] N. Nagase, A. Sasaki, K. Yamashita, et al., Isolation and species distribution of staphylococci from animal and human skin. J. Vet. Med. Sci, 2002, 64: 245-250.

[4] O. Aspevall, H. Hallander, V. Gant, et al., European guidelines for urinalysis: A collaborative document produced by European clinical microbiologists and clinical chemists under ECLM in collaboration with ESCMID. Clin. Microbiol. Infect, 2001, 7: 173-178.

[5] B. Guirguitzova, D. Chankova, and B. Zozikov, Staphylococci as uropathogens - frequency of isolation in hospitalized patients and sensitivity to antimicrobial agents. Ann. Urol. (Paris), 2002, 36: 341-347.

[6] A. Al-Hamadani, A. Al-Bideri, and W. Al-Janabi, Isolation and Identification of bacteria from patients with transitional cells carcinoma of urinary bladder. $Q M J$, 2001: 7:11.

[7] R. M. Donlan, Biofilms. Microbial life on surfaces. Emerging Infectious Diseases, 2002, 8: 881.

[8] N. Høiby, O. Ciofu, H. Johansen, et al., The clinical impact of bacterial biofilms. Int J Oral Sci, 2011, 3: 5565.

[9] J. Denstedt, T. Wollin, and G. Reid, Biomaterials used in urology: current issues of biocompatibility, infection, and encrustation. J Endourol, 1998, 12: 493-500.

[10] L. Hall-Stoodley, J. W. Costerton, and P. Stoodley, Bacterial biofims: From the natural environment to infectious diseases. Nature Reviews Microbiology, 2004, 2(2): 95-108.

[11] WHO, Antimicrobial resistance: Global report on surveillance 2014. World Health Organization, 2014: $1-257$.

[12] S. Golia, S. Asha, and B. Kamath, A study of biofilm production in clinical isolates of Staphylococci at a tertiary care hospital, Bangalore. Int J Res Med Sci, 2015, 3(2): 470-474

[13] S. Bakir, F. Ali, Comparison of different methods for detection of biofilm production in multi-drug resistance bacteria causing pharyngotonsillitis. International Journal of Research in Pharmacy and Biosciences, 2016, 3(2): 1322.

[14] M. Mohammed, M. Rasheed, and M. Nadeer, Detection of biofilm- associated genes in clinical staphylococcus aureus isolated from Iraqi patients. I.J.S.N., 2015, 6(1): 19-22.

[15] B. Forbes, D. Sahm, and A. Weissfeld, Bailey and Scotts' 
diagnostic microbiology, $12^{\text {th }}$ ed. Elsevier, 2007.

[16] D.J. Freeman, F.R. Falkiner and C.T. Keane, New method for detecting slime production by coagulase negative staphylococci. J Clin Pathol, 1989, 42:872-874.

[17] G. Christensen, W. Simpson, and J. Younger, Adherence of coagulase-negative Staphylococci to plastic tissue culture plates: a quantitative model for the adherence of Staphylococci to medical device. Journal Clinical Microbiology, 1985, 22(6): 996-1006.

[18] A. Baur, W. Kirby, J. Sherris, et al., Antibiotic susceptibility testing by a standardized single dick method. Am. J. Clin. Pathol., 1966, 45: 493-496.

[19] CLSI, Performance standards for antimicrobial susceptibility testing. M100, $27^{\text {th }}$ ed. Clinical and Laboratory Standards Institute, 2017.

[20] S. Stepanovic, V. Dimitrijevic, and D. Vukovic, Staphylococcus sciuri as a part of skin, nasal and oral flora in healthy dogs. Vet. Microbiol, 2001, 82: 177-185.

[21] G. Gad, M. El-Feky, and M. El-Rehewy, Detection of icaA, icaD genes and biofilm production by Staphylococcus aureus and Staphylococcus epidermidis isolated from urinary tract catheterized patients. $J$ Infect Dev Ctries, 2009, 3(5): 342-351.

[22] S. Bose, M. Khodke, and S. Basak, Detection of biofilm producing staphylococci: need of the hour. Journal of Clinical and Diagnostic Research, 2009, 3: 1915-1920.

[23] D. Stickler, Bacterial biofilms in patients with indwelling urinary catheters, nature clinical practice. UROLOGY, 2008, 5: 11.

[24] C. Arciola, L. Baldassarri, and L. Montanaro, Presence of icaA and icaD genes and slime production in a collection of staphylococcal strains from catheter-associated infections. J Clin Microbiol, 2001, 39: 2151-2156.

[25] R. Yazdani, M. Oshaghi, and A. Havayi, Detection of icaAD gene and biofilm formation in Staphylococcus aureus isolates from wound infections. Iranian $\mathrm{J} \mathrm{Publ}$ Health, 2006, 35: 25-28.

[26] C. Heilmann, Molecular basis of biofilm formation by Staphylococcus epidermidis. M. Wilson, D. Devine, Eds., Medical implications of biofilms. Cambridge University Press, 2003: 110-135.

[27] L. Montanaro, C. Arciola, and E. Borsetti, A polymerase chain reaction (PCR) method for the identification of collagen adhesin gene (cna) in Staphylococcus-induced prosthesis infections. New Microbiol, 1998, 21: 359-363.

[28] J. O'Gara, H. Humphreys, Staphylococcus epidermidis biofilms: importance and implications. Journal of Medical microbiology, 2001, 50: 582-587.

[29] J. del Pozo, R. Patel, The challenge of treating biofilm associated bacterial infections. Clin. Pharmacol. Ther, 2007, 82: 204-209.

[30] F. Corona, J.L. Martinez, Phenotypic resistance to antibiotics. Antibiotics, 2013, 2: 237-255.

[31] K. Smith, L. Hunter, Efficacy of common hospital biocides with biofilms of MDR clinical isolates. $J$ Med Microbiol, 2008, 57: 966-973.

[32] J. Parra-Ruiz, C. Vidaillac, and M. Rybak, Macrolides and staphylococcal biofilms. Rev Esp Quimioter, 2012, 25(1): 10-16.

[33] Q. Wang, F. Sun, and Y. Liu, Enhancement of biofim formation by subinhibitory concentrations of macrolides in icaADBC positive and -negative clinical isolates of Staphylococcus epidermidis. Antimicrob Agents Chemother, 2010, 54: 2707-2711.

[34] I. Al-Azawi, Antibiotic susceptibility pattern and mecA gene detection in methicillin resistance Staphylococcus aureus (MRSA) Isolated from burn and wound in AlDiwaniya city. Journal of Babylon University/Pure and Applied Sciences, 2013, 3(21).

[35] K. Cihalova, D. Chudobova, and P. Michalek, Staphylococcus aureus and MRSA Growth and Biofilm Formation after Treatment with Antibiotics and SeNPs. Int. J. Mol. Sci., 2015, 16: 10.

[36] A. Corbin, B. Pitts, and A. Parker, Antimicrobial penetration and efficacy in an in vitro oral biofilm model. Antimicrob. Agents Chemother, 2011, 55(7): 3338-3344.

Copyright $₫$ Ibtisam Habeeb Al-Azawi, Adnan Hamad AlHamadani, and Shaimaa Obaid Hasson. This is an open-access article distributed under the terms of the Creative Commons Attribution License, which permits unrestricted use, distribution, and reproduction in any medium, provided the original author and source are credited. 